\title{
Cervical Spine Immobilization in Sports Related Injuries: Review of Current Guidelines and a Case Study of an Injured Athlete
}

\author{
J.S. Bhamra ${ }^{*}, 1$, Y. Morar ${ }^{2}$, W.S. Khan ${ }^{1}$, K. Deep ${ }^{2}$ and A. Hammer ${ }^{2}$ \\ ${ }^{I}$ Royal National Orthopaedic Hospital, Brockley Hill, Stanmore, Middlesex, HA7 4LP, UK \\ ${ }^{2}$ Medway Maritime Hospital, Windmill Road, Gillingham, Kent, ME7 5NY, UK
}

\begin{abstract}
Cervical spine immobilization is an essential component of the $\operatorname{ATLS}^{\circledR}$ system. Inadequate training in the management of trauma calls and failure of early recognition can have disastrous consequences. Pre-hospital personnel are routinely involved more in the assessment and stabilization of patients in comparison to other health care professionals.

This case study and review highlights the importance of early recognition, assessment and correct stabilization of cervical spine injuries both in the field and during the initial assessment in hospital.

Inadequate assessment, immobilization and lack of standard guidelines on the management of suspected cervical spine trauma can result in secondary injury. Regular assessment and training of pre-hospital and medical personnel is essential to the proper management of these potentially devastating injuries.
\end{abstract}

Keywords: Athletes, case report, guidelines, review, sports related injuries, traumatic cervical spine injury.

\section{BACKGROUND}

The National Spinal Cord Injury Statistical Center (NSCISC) reports an approximated annual figure of 12,000 new cases of spinal cord injury. Of these, $7.6 \%$ are estimated to be caused by traumatic sports related events [1]. Injury to the cervical spine is, however rare, occurring in about $2-4 \%$ of all blunt trauma cases [2]. Ghiselli et al., report an incidence of sports related cervical spine injuries at 1000 per year, with the majority of these being due to diving and swimming [3].

Spinal cord injuries due to sports are the fourth most common cause of visits to the emergency department, with the leading cause remaining as road traffic accident related. In relation to these statistics the incidence of cervical spine injuries are rare, with most of these being minor. Those that occur frequently culminate as ligamentous or muscular sprains and/or soft tissue contusions [4]. Recent data suggests the mean age of injury is 24 years, but in reality the first three decades of life carry the highest risk of injury.

Numerous sports have been identified as carrying a high risk to the cervical spine. These include football, ice hockey, rugby, skiing, snowboarding and equestrian sports $[2,3]$. High impact sports such as these carry obvious risks, but due to the ever increasing popularity of these sports the frequency of injuries continues to grow.

A catastrophic cervical spine injury is defined as a "structural distortion of the cervical spinal column associated with damage to the spinal cord". A significant traumatic

*Address correspondence to this author at the Royal National Orthopaedic Hospital, Brockley Hill, Stanmore, Middlesex, HA7 4LP, UK;

Tel: 07968353356; Fax: 02089542300; E-mail: j_s_bhamra@hotmail.com episode involving the cervical spine can potentially cause devastating and/or irreversible neurological sequelae. This can ultimately impact on and alter an athlete's life [5].

Over the past few decades, the incidence of severe or catastrophic cervical spine injuries is declining amongst the contact sports. This is most likely due to an increased awareness amongst the sports community, but also because of 'play modifications', the development of governing rules, education of proper techniques, offseason conditioning and the improvement of protective gear and equipment. Important work carried out by Schneider in the 1960's helped achieve this significant reduction in cervical spine injuries [6]. Nevertheless, the incidence of severe cervical spine injuries remains highest amongst football related injuries in comparison to sports such as gymnastics, wrestling and ice hockey. This, in part, is due to a greater number of participants within the football group. Current data approximates 1,500,000 high school and middle school participants, with more than 75,000 college football players in the United States (U.S.) $[4,7]$.

Within this review of cervical spine injuries in sports, we include a case study to highlight the management process of an injured athlete on the field with a discussion on the pitfalls that can occur along the journey to the emergency department. In addition, we present the current guidelines and recommendations for managing such injuries and highlight the need for absolute awareness in all medical personnel involved in this process, both as participant and spectator.

\section{INITIAL ASSESSMENT}

It is of paramount importance that any 'potentially' catastrophic injuries are recognized early. Current recommendations suggest that excessive movements that 
may potentially exacerbate initial spinal injury and result in a secondary spinal cord injury are to be avoided [7]. Secondary spinal cord damage can be caused during extrication, resuscitation, transport and evaluation of patients with suspected spinal instability. Thus, it is mandatory to protect the cervical spine before the patient arrives in the hospital. Many methods of achieving cervical spine immobilization have been described in the literature. Common strategies used include manual stabilization with the use of orthotic devices such as a hard cervical collar, head blocks, strapping and spinal boards. The suggested time frame for immobilization in a cervical collar currently ranges from 3 to 72 hours [8].

Early assessment of a cervical spine injury can be difficult and challenging, particularly if there are no obvious signs and symptoms. Initial assessment on the field, otherwise known as the 'primary survey', involves a succinct assessment of the conscious level (Glasgow Coma Scale, GCS), airway, breathing and circulation - "the ABC approach". This is used to identify any life-threatening injuries quickly. A thorough on-field evaluation must also include an examination of the cognitive and memory processes and cranial nerve function. As in the majority of cases, if the patient is conscious at the initial assessment, the GCS can be determined through direct questioning. Any neurological deficit may be assessed through questioning about extremity parasthesia, painful dysthesthesias, weakness and neck pain. Furthermore, suspicion of a significant traumatic cervical spinal injury should be suspected in athletes that display spasm, tenderness, or loss of range of motion. These should therefore be managed accordingly. Other red flag signs to be wary of include severe neck pain and cervical tenderness, rigid cervical spasm and persistent apprehension [9].

On-field clinical examination can prove difficult to conduct, due to the restrictions on movement. In such cases, a limited examination may identify any obvious neurological injury (gross motor weakness, numbness and cervical spine pain). Initial assessment should also include the identification of a concomitant head injury due to any trauma. An associated significant brain injury is always a possibility. If the patient is compliant, a brief history and account of events is taken on-field, with particular attention paid to the mechanism of injury (for example, 'speartackling'). Collateral history from witnesses plays a vital role in providing further detail which can prove to be significant later on. Based on these findings, the decision to transport the athlete is taken. Current literature suggests that any unconscious or injured athlete that complains of numbness, paralysis, weakness or neck pain should be treated as if a cervical spine fracture is present (i.e. an unstable spinal injury) [7].

In addition, failure to manage a significant neck injury adequately may compromise an athlete's cardiac and respiratory function. Therefore, all medical personnel involved in such a catastrophic situation needs to be well trained, educated and be prepared to deal with any unexpected events that may occur during the transfer.

\section{MECHANISM OF INJURY}

Serious cervical injury is reported to occur as a result of axial load, or a large compressive force on the head. This mechanism carries a higher associated risk of injury when the neck is slightly flexed (at approximately $30^{\circ}$ ), due to the spine being brought out of its normal lordotic alignment and configuration upon impact. The result is improper force distribution to the thorax; the cervical spine is placed in a straight line due to flexion with the supporting musculature and soft tissues unable to cope with absorbing the force. This then manifests in 'pinching' of the spinal cord with spinal cord neuropraxia ensuing [7]. Such an accelerationdeceleration injury is usually secondary to high velocity collisions between players, with acceleration usually causing a whiplash (type of extension force) and deceleration resulting due to flexion forces [10].

Compression of the cervical spine between the body and a rapidly decelerating head is a primary cause of cervical fracture, dislocation and quadriplegia, as described by Torg et al., When the impact force is greater than the yield strength of the vertebrae, a fracture is likely with or without dislocation. Neurologic damage can occur with the presence of a fracture, bone fragments or herniated disc contents that encroach of the spinal cord $[10,11]$.

\section{HOSPITAL MANAGEMENT}

Even after reaching hospital, patients can be immobilized in a hard cervical collar for relatively long periods of time until they are clinically and radiologically assessed. In many hospitals it is common practice that even at this stage, removal of the spinal board with proper positioning of patient and application of appropriate orthosis (correctly sized \& applied collar) is not instituted until the specialist on-call team has reassessed and managed the patient further. In addition to this, is the added long wait during the triage time in Accident \& Emergency departments before the patient is reviewed. An exception to this is the trauma alert call, where patients are seen instantly. Those factors that prolong proper management result in unnecessary patient suffering. We describe such a case with rather more dramatic circumstances.

\section{CASE STUDY}

A 32-year-old rugby player was involved in a scrum which collapsed. Several other players also fell onto him. At the time of injury he stated he had "heard a crack in his neck". He was found lying face down in a prone position with a torticollis deformity. He complained of neck pain with any attempted movement. He was assessed at the scene by the paramedic crew who could not elicit any sensory or motor deficit. His GCS was $15 / 15$ and there was no history of loss of consciousness. A cervical spine injury was suspected and hence stabilization in a hard collar with headblocks was instigated. The patient was strapped on a spinal board in the prone and torticollis position in which he was found (Fig. 1). He was transported to the local Accident \& Emergency department where he was triaged. Only after a two hour wait was he assessed. Radiographs of his cervical spine were taken without altering his lying position 


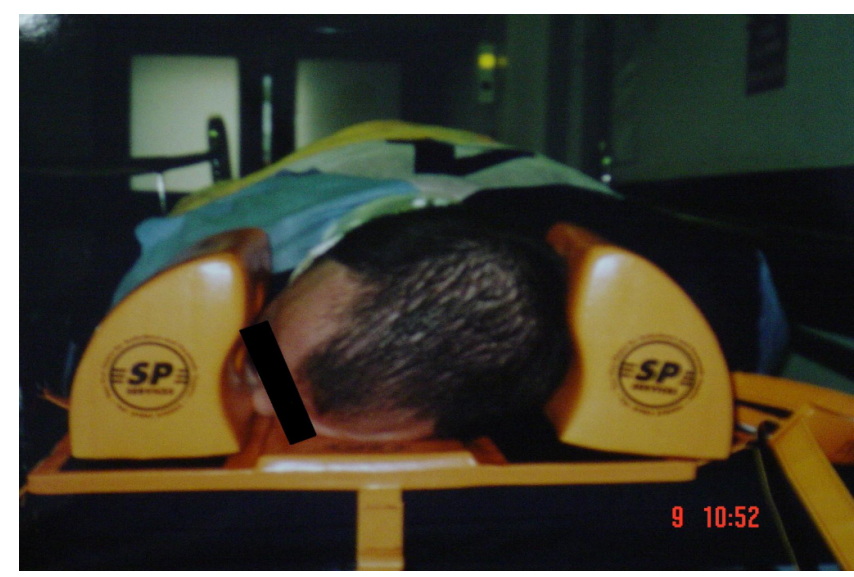

Fig. (1). Immobilized patient lying in prone position; as found in the field by paramedics.

He was subsequently referred to the on-call Orthopaedic team for definitive management. At this stage he was log rolled into a supine position and a new cervical collar was correctly applied. The spinal board was finally removed after a further two hours. Repeat radiographs of his cervical spine were taken in a supine position and a diagnosis of atlantoaxial dislocation was made. Neurological assessment using the American Spinal Injuries Association (ASIA ${ }^{\circledR}$ ) system confirmed no neurological deficit [12]. The dislocation was reduced after computerized tomography (CT) scan confirmed the diagnosis in theatre (Fig. 2). Definitive stabilization was done with a Sub Occipito Mandibular Immobilization (SOMI) brace which was worn for six weeks, with a good outcome.

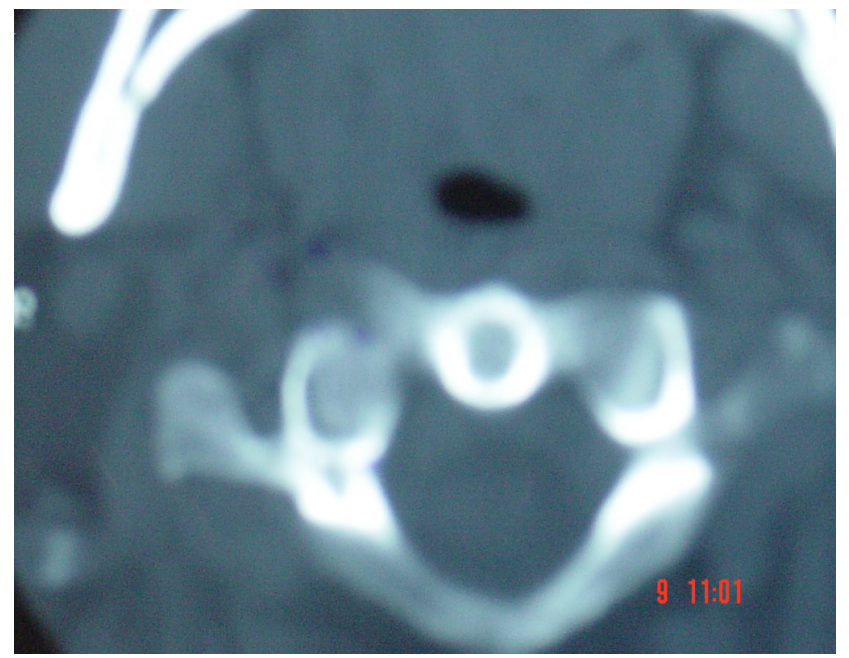

Fig. (2). Commuted Tomography (CT) scan demonstrating atlantoaxial dislocation.

\section{ATLANTO-AXIAL DISLOCATION}

Atlanto-Axial Injury (AAI) is a relatively rare but serious injury. Certain conditions have been associated with this injury. Studies have shown that $10-25 \%$ of patients with trisomy 21 have AAI and approximately $25 \%$ of patients suffering from rheumatoid arthritis have AAI, attributed to a chronic inflammatory process. These conditions can increase the risk of instability due to an increased atlanto-axial joint laxity. There are also further associations with infections, congenital skeletal dyspasias, Marfan's syndrome and acute inflammatory processes that affect the retropharyngeal, neck or pharyngeal pouches $[13,14]$. There was no relevant past medical history or any disease correlation in the case study that we discuss.

Atlanto-Axial dislocation/subluxation is radiologically identified as the increased mobility or laxity between the body of the first cervical vertebra ( $\mathrm{C} 1$ - atlas) and the odontoid process of the second cervical vertebra (C2 - axis) [15]. The subluxation can be anterior, posterior, or lateral and symptoms occur as a result of cervical cord impingement. In this case report there was no neurological deficit.

During extremes of cervical flexion or extension, competent transverse and alar ligaments limit posterior translation of the odontoid process. Incompetent ligaments or a damaged odontoid process can allow for significant translation and potential damage in cases of cervical hyperflexion or hyperextension in which axial compression is delivered to the head and cervical spine. Given the potentially serious sequelae of significant atlanto-axial dysfunction, patients with defined instability are restricted from participating in contact sports and in sports requiring significant cervical flexion or extension [16].

\section{THE SPINAL BOARD AND POSITIONING}

The injured athlete should always be secured to a rigid spinal board. This should be done in a manner that allows adequate cervical spine immobilisation but full access to the airway. Extensive research has been performed in an attempt to determine the optimal position for the cervical spine to allow maximal space for the spinal cord. Studies performed by DeLorenzo et al., using MRI to determine the optimal position of the cervical spine with a cross-sectional area of the cervical spinal canal versus the spinal cord showed that a maximum area available for the spinal cord was achieved with slight flexion, corresponding to raising the occiput $2 \mathrm{~cm}$ [17]. In contrast, Tierney et al., [18] concluded that most space was present with the occiput at zero $\mathrm{cm}$ evaluation, taking into account equipment considerations in American football injuries unlike the previous study group [7]. In such cases, it is therefore advised that the helmet and shoulder pads should be left on, in sports that use protective gear.

\section{CERVICAL SPINE CLEARANCE}

Clinical criteria for hospital clearance of the cervical spine are based on the mechanism of injury. Hoffman's criteria (Table 1) involves clinical examination and clearance of the cervical spine in low risk patients NEXUS $^{\odot}-$ National Emergency X-radiography Utilization Study). These criteria include assessment of a non-intoxicated patient with no midline spinal or paraspinal tenderness, GCS $15 / 15$, no neurological deficit, no other painful distracting injuries [8]. The negative predictive value of clinical examination is almost $100 \%$, suggesting a low probability of cervical spine injury [8]. Based on these suggestions, fully conscious athletes with cervical trauma can be cleared without radiographic investigations if the NEXUS criteria are met. However, this is in contrast to the Advanced Trauma Life Support guidelines (American College of Surgeons), that recommend all patients sustaining a traumatic injury above the clavicle should have a cervical spine radiograph (AP, lateral and odontoid peg view) [19]. In 
a neurologically stable patient, flexion and extension lateral views may also be performed to assess instability [9].

Table 1. According to NEXUS ${ }^{\odot}$ Low-Risk Criteria Cervical Spine Radiography is Indicated for Trauma Patients Unless they Exhibit All of the Following Criteria

\begin{tabular}{|c|l|}
\hline $\mathbf{1}$ & No posterior midline cervical tenderness \\
\hline $\mathbf{2}$ & No evidence of intoxication \\
\hline $\mathbf{3}$ & Normal level of alertness \\
\hline $\mathbf{4}$ & No focal neurologic deficit \\
\hline $\mathbf{5}$ & No painful distracting injuries \\
\hline
\end{tabular}

Contents of the spinal cord can be evaluated with a contrast-enhanced computed tomography (CT) scan or magnetic resonance imaging (MRI). A study performed by Holmes et al., [20, 21] demonstrated a 100\% correlation with MRI identifying cervical ligamentous and spinal cord injury in patients evaluated for traumatic cervical spine injuries [9].

\section{INJURY PREVENTION}

Sports related spinal injuries can be prevented with proper technique, instruction and training. Contact organized sports such as football and rugby carry the advantages of ritualized training that allows coaches to convey controlled training methods and to emphasize proper manoeuvres to reduce accidents. Techniques using correct positioning of blocking and tackling to avoid hyperflexion type injuries and initial head contact must be employed; 'spear-tackling' has almost completely been eradicated from these sports with the introduction of rules to avoid this. It is now also common practice in many sports to routinely have injury prevention programs. These address many aspects of injury prevention, and in relation to the cervical spine, carry out offseason neck-strengthening exercises. The continuing improvements in safety sports wear and equipment, both in design and manufacture have also contributed to a reduction in traumatic cervical spine injuries [7].

\section{DISCUSSION}

Cervical spine injuries can lead to substantial morbidity and mortality. In athletes especially, it can end or change the future of their career [6]. Therefore, failure to properly recognize these injuries with poor provision of early care may lead to devastating complications. These will be discussed later.

In the case that we present, the initial care provided in the field by paramedics was satisfactory but the patient suffered unnecessarily for more than two hours whilst being kept in a very uncomfortable prone position on a hard spinal board, even after being re-assessed in the Accident \& Emergency department. The associated adverse effects with cervical spine immobilization are well documented. These include skin necrosis, pressure ulcers, risk of aspiration, marginal mandibular nerve palsy and potential for increased intracranial pressure [22]. Previous practice and management of such injuries maintained that if a conscious athlete could reposition his head to neutral position without pain or resistance, then they were encouraged to do so. More recently, a more cautious approach has been observed since it has been assumed that an unstable spinal injury can be converted into a more severe injury if the athlete is mishandled [23]. The appropriateness of repositioning the head into a neutral position by paramedics in the field should be assessed on an individual basis and only then the decision to immobilize the patient in the position found should be undertaken.

Current practice suggests that the immobilization of a prone athlete and movement from prone to supine should be done with a minimum of four persons. To immobilize a prone athlete, the rescuer at the head should maintain the head/neck complex in the position in which it was found [24]. If a prone athlete is not breathing, a log roll should be performed immediately. Unless the immobilization device is readily available, the athlete must be log rolled into a supine position on the playing surface and then moved a second time onto the long back board (the chances of secondary injury increase with each movement). If the athlete is conscious and stable, the log roll should be delayed until the backboard is available [25]. It is common practice to load the stretcher in the ambulance with the athlete's head at the rear to avoid axial loading during ambulance braking.

\section{CONCLUSION}

An emergency plan should be in place to ensure smooth initial management of an athlete with suspected cervical spine injury. This plan must be established, approved, revised and rehearsed on a regular basis. It must be practical and flexible to adapt to any emergency situation. There must be written documents that are distributed to key personnel.

We recommend that all medical staff involved in the initial stages of hospital care (including triage), should receive the necessary training, education and courses $\left(\mathrm{ATLS}^{\circledR}\right)$ to recognize and manage cervical spine injuries and to the instigate the appropriate management. There is a need for readily available guidelines in all Emergency departments. Best practice dictates that Emergency departments should audit their acute management of cervical spine injuries to highlight current deficiencies and to ensure appropriate training and education to improve practice.

\section{CONFLICT OF INTEREST}

The authors confirm that this article content has no conflict of interest.

\section{ACKNOWLEDGEMENTS}

Declared none.

\section{REFERENCES}

[1] NSCISC National Spinal Cord Injury Statistical Center: Facts and Figures at a Glance. https://www.nscisc.uab.edu/PublicDocument s/fact_figures_docs/Facts\%202012\%20Feb\%20Final.pdf (Accessed on: September 5, 2012).

[2] Agarwal A, Deep K. A New clinical sign in traumatic atlantoaxial subluxation and dislocation. J Bone Joint Surg Br 2006; 88-B (Suppl I): 154.

[3] Ghiselli G, Schaadt G, McAllister DR. On-the-field evaluation of an athlete with a head or neck injury. Clin Sports Med 2003; 22(3): 445-65.

[4] Zahir U, Ludwig SC. Sports-related cervical spine injuries:on-field assessment and management. Semin Spine Surg 2010; 22: 173-80.

[5] Banerjee R, Palumbo MA, Fadale PD. Anatomy, and diagnosis catastrophic cervical spine injuries in the collision sport athlete, 
Part 1 : epidemiology, functional anatomy and diagnosis. Am J Sports Med 2004; 32: 1077.

[6] Schneider RC. Head and Neck Injuries in Football: Mechanisms, Treatment and Prevention. Baltimore: Williams \& Wilkins 1973.

[7] Bailes JE, Petschauer M, Guskiewicz, Marano G. Management of cervical spine injuries in athletes. J Athl Train 2007; 42(1): 126-34.

[8] McHugh TP, Taylor JP. Unnecessary out-of-hospital use of full spinal immobilization. Acad Emerg Med 1998; 5: 278-80.

[9] Chang D, Bosco III JA. Cervical Spine Injuries in the Athlete. Bull NYU Hosp Jt Dis 2006; 64(3-4): 119-29.

[10] Villavicencio AT, Hernández TD, Burneikiene S, Thramann J. Neck pain in multisport athletes. J Neurosurg Spine 2007; 7(4): 408-13.

[11] Torg JS, Vegso JJ, O'Neill MJ, Sennett B. The epidemiologic, pathologic, biomechanical, and cinematographic analysis of football-induced cervical spine trauma. Am J Sports Med 1990; 18: 50-7.

[12] American Spinal Injury Association ${ }^{\circledR}$. Standard Neurological Classification of Spinal Cord Injury. Available at: http://www.as iaspinalinju ry.org [Accessed on: September $5^{\text {th }}, 2012$ ].

[13] Davis JW, Phreaner DL, Hoyt DB, Mackersie RC. The etiology of missed cervical spine injuries. J Trauma 1993; 34: 342-6.

[14] Banit D, Murrey D, Darden II B. Atlantoaxial Instability. Available at: http://emedicine.medscape.com/article/1265682-overview [Accessed September $\left.5^{\text {th }}, 2012\right]$.

[15] Achar S, Achar SK. Atlantoaxial instability. The Five Minute Sports Medicine Consult. Philadelphia, Lippincott: Williams and Wilkins. 2000; pp. 24-5.
[16] Koutures CG, Simpson CD, Munyak J. Atlantoaxial Injury and Dysfunction. Available at: http://emedicine.medscape.com/article/ 93546-overview\#a0107 [Accessed on: September $5^{\text {th }}, 2012$ ].

[17] De Lorenzo R. A review of spinal immobilization techniques. J Emerg Med 1996; 14: 603-13.

[18] Tierney RT, Mattacola CG, Sitler MR, Maldjian C. Head position and football equipment influence cervical spinal-cord space during immobilization. J Ath1 Train 2002; 37: 185-9.

[19] Advanced Trauma Life Support ${ }^{\mathbb{R}} .9^{\text {th }}$ ed. Student Course Manual. American College of Surgeons Committee on Trauma 2008.

[20] Holmes JF, Mirvis SE, Panacek EA. Variability in computed tomography and magnetic resonance imaging in patients with cervical spine injuries. J Trauma 2002; 53(3): 524-9.

[21] Langer PR, Fadale PD, Palumbo MA. Catastrophic neck injuries in the collision sport athlete. Sports Med Arthrosc 2008; 16(1): 7-15.

[22] Hoffman JR, Mower WR, Wolfson AB, Todd KH, Zucker MI. Validity of a set of clinical criteria to rule out injury to the cervical in patients with blunt trauma. National Emergency X-Radiography Utilization Study Group. N Engl J Med 2000; 343: 94-9.

[23] Webber-Jones JE, Thomas CA, Bordeaux RE Jr. The management and prevention of rigid cervical collar complications. Orthop Nurs 2002; 4(21): 19-26.

[24] Schriger DL. Immobilizing the cervical spine in trauma: should we seek an optimal position or an adequate one? Ann Emerg Med 1996; 28: 351-3

[25] Kleiner DM, Almquist JL, Bailes J. Prehospital care of the spine injured athlete: A document from the inter-association task force for appropriate care of the spine injured athlete. National Athletic Trainers Association, Dallas, TX 2001; pp. 5-31.

(C) Bhamra et al.; Licensee Bentham Open

This is an open access article licensed under the terms of the Creative Commons Attribution Non-Commercial License (http://creativecommons.org/licenses/by-nc/3.0/) which permits unrestricted, non-commercial use, distribution and reproduction in any medium, provided the work is properly cited. 